Tohoku J. Exp. Med., 2006, 209, 89-97

\title{
Leupeptin, a Calpain Inhibitor, Protects Inner Ear Hair Cells from Aminoglycoside Ototoxicity
}

\author{
Junko Momiyama, Toshimitsu Hashimoto, Atsushi Matsubara, Kazunori Futai, \\ Atsushi Namba and Hideichi Shinkawa \\ Department of Otorhinolaryngology, Hirosaki University School of Medicine, \\ Hirosaki, Japan
}

\begin{abstract}
Momiyama, J., Hashimoto, T., Matsubara, A., Futai, K., Namba, A. and Shinkawa, H. Leupeptin, a Calpain Inhibitor, Protects Inner Ear Hair Cells from Aminoglycoside Ototoxicity. Tohoku J. Exp. Med., 2006, 209 (2), 89-97 — Inner ear hair cells play a major role in the auditory pathway that converts sound stimulation into electrical signals, and then into a neural code. However this function is often lost by aminoglycoside ototoxicity. The injury of inner ear hair cells from aminoglycoside treatment is considered apoptosis, and caspase is an important participant in the apoptosis pathway in many organs. It has been reported that calpain, a calcium-dependent protease, is essential for mediation and promotion of cell death. The purpose of the present study was to investigate effects of caspase and calpain inhibitors on the inner ear hair cells after aminoglycoside treatment, and to explore the cell death pathway. Cochlea explant cultures were prepared from mice of postnatal 6 days, cultured with neomycin and/or protease inhibitors, and then stained with phalloidin-fluorescein isothiocyanate (phalloidin-FITC), which was used as a marker to identify surviving hair cells. We demonstrated that neomycin $(0.1-1 \mathrm{mM})$ reduced the number of outer hair cells in a dose-dependent manner. Furthermore, we showed that leupeptin, a calpain inhibitor, significantly protects against the neomycin-induced loss of outer hair cells, whereas a caspase inhibitor was effective only against a lower concentration of neomycin $(0.2 \mathrm{mM})$. Using the TdT-mediated dUTP-biotin nick and labeling method, we also found that a calpain inhibitor, but not a caspase inhibitor, prevents apoptotic DNA fragmentation after treatment with $1 \mathrm{mM}$ neomycin. These results suggest that calpain, rather than caspase, may be responsible for apoptosis induced by aminoglycoside. Thus, leupeptin may prevent hearing loss from aminoglycoside ototoxity. —— apoptosis; calpain; leupeptin; aminoglycoside; cochlea (C) 2006 Tohoku University Medical Press
\end{abstract}

The cochlea is a sensory organ in the inner ear that converts sound stimulation into electrical signals, and then into a neural code in the central auditory pathway. This process is based upon the ion transport system. Electrical phenomena in the cochlea include the endocochlear potential, recep- tor potential of the sensory hair cells, outer hair cells motility, and neurotransmission, all of which are involved in the maintenance of the intra- and extracellar chemical and electrical environment (Ikeda 2004). But this function is often lost by sound overstimulation, aging and side effects of

Received November 25, 2005; revision accepted for publication March 18, 2006.

Correspondence: Junko Momiyama, M.D., Ph.D., Department of Otorhinolaryngology, Hirosaki University

School of Medicine, Zaifu-cho 5, Hirosaki 036-8562, Japan.

e-mail: junkosan@r66.7-dj.com 
drugs such as cisplatin, loop diuretic and aminoglycoside.

Aminoglycosides are therapeutically useful antibiotics due to their low cost and effectiveness in treating Gram-negative bacterial infections. However, their clinical usefulness is limited because they are nephrotoxic and ototoxic. To find a strategy to prevent ototoxicity, it is necessary to understand the mechanisms underlying aminoglycoside ototoxicity.

A few years ago, it was unknown what type of cell death, apoptosis or necrosis, occurred in cochlear hair cells following aminoglycoside exposure. However, recently it has been shown in several studies that aminoglycoside induces apoptosis in inner ear hair cells (Forge 1985; Li et al. 1995; Nakagawa et al. 1997, 1998; Lenoir et al. 1999; Forge and Li 2000). Many kinds of enzymes associated with apoptosis have already been identified (Salvesen and Dixit 1997; Raff 1998; Johnson 2000). Of those, the most well known protease is caspase. More recently, however, evidence has accumulated that non-caspase, proteases including calpains, also participate in mediating and promoting cell death (Johnson 2000). To investigate the apoptotic mechanisms of ototoxic and/or acoustic injury, protease inhibitors such as leupeptin, which is a calpain inhibitor, and Boc-Asp-O-CH3-fluoromethyl ketone (BAF), which is a caspase inhibitor, are generally used (Liu et al. 1998; Salvi et al. 1998; Cheng et al. 1999; Wang et al. 1999; Ding et al. 2002; Matsui et al. 2002). It has been reported that leupeptin protects inner ear hair cells from gentamicin ototoxicity in vitro (Ding et al. 2002). It has also been shown that the inhibition of caspase promotes inner ear hair cell survival in the chick after neomycin treatment (Matsui et al. 2002).

A previous study has been performed to compare effects of calpain and caspase inhibitors in inner ear hair cell loss induced by hypoxia and neurotrophin-withdrawal (Cheng et al. 1999). However, comparison of those effects in cochlear hair cell death due to aminoglycoside exposure has never been reported. The aim of the present study was to show that aminoglycoside induces apoptosis in cochlear hair cells and to investigate the roles of calpain and caspase in this hair cell loss.

\section{Materials and Methods}

\section{Cochlear culture}

This study was carried out in accordance with the Guidelines for Animal Experimentation at Hirosaki University.

Cochlea explant cultures were prepared from 84 postnatal 6-day C57BL/6J mice. Mice were deeply anesthetized by inhalation of diethyl ether and then sacrificed by cervical transection. Using forceps, the cochlear was dissected from the temporal bone with the aid of a stereomicroscope and was transferred to a dish containing $0.01 \mathrm{M}$ sodium phosphate buffered saline ([PBS], Invitrogen, Carlsbad, CA, USA). Then the otic capsule was carefully removed. The organ of corti was peeled off from the modiolus and the stria vascularis was also removed. Since hair cells in the apex are resistant to aminoglycoside (Romand and Chardin 1999; Kopke et al. 1999), in this study we used the basal turn. The tissue pieces were attached to glass plates (FALCON, Billerica, MA, USA) coated with poly-D-lysine and Ornithine. The cochlear explants were cultured in Dulbecco's Modified Eagle's Medium (Invitrogen) supplemented with D-glucose (WAKO, Osaka, final concentration: 6 $\mathrm{g} / \mathrm{l})$. These culture dishes were put into an incubator under a $5 \% \mathrm{CO}_{2}$ atmosphere. The temperature was set at $37^{\circ} \mathrm{C}$ and culture media was not renewed. Cultures maintained in normal medium for 4 days were used as a control. After 2 days in normal medium, neomycin sulfate (neomycin, Sigma, St. Louis, MO, USA) of seven different concentrations $(0.05,0.1,0.2,0.3,0.4,0.5,1.0$ $\mathrm{mM}$ ) were each added to ten explants, which were then cultured for 48 hours. The cochlear explants were also cultured with leupeptin (calpain inhibitor, Sigma) or BAF (caspase inhibitor, Enzyme System Products, Irvine, CA, USA) to investigate the effect of each against neomycin damage on inner ear hair cells and to determine their effective doses. Following 2 days of culturing with leupeptin $(2,4,6,10,40 \mu \mathrm{g} / \mathrm{ml})$, the explants were exposed to neomycin $(0.2$ or $1.0 \mathrm{mM})$ as previously mentioned. Likewise, cochlear explants were cultured with BAF (200 $\mu \mathrm{M}$ or $500 \mu \mathrm{M})$ in place of leupeptin. We referred to previous studies for selecting these doses (Liu et al. 1998; Salvi et al. 1998; Cheng et al. 1999; Wang et al. 1999). 


\section{Phalloidin-FITC staining}

The cultures were fixed with $4 \%$ paraformaldehyde at room temperature for $30 \mathrm{~min}$ and then incubated in t-Octylphenoxypolyethoxyethanol (Sigma) dissolved in PBS at $1 \%$ (PBS-TritonX100) for $15 \mathrm{~min}$. They were then stained with $3.0 \mu \mathrm{g} / 1$ phalloidin-fluorescein isothiocyanate (phalloidin-FITC, Sigma) for $45 \mathrm{~min}$. The dishes were covered with aluminum foil as the phalloidin is light sensitive. The cochlear explants were washed twice in PBS and observed using a laser microscope (LSM310 laser scan system ZEISS, Oberkochen, Baden-Württemberg, Germany) with appropriate filters for FITC (absorption: $488 \mathrm{~nm}$, emission: $522 \mathrm{~nm}$ ). Hair cells were counted as missing if there was a total absence of stereocilia bundle labeling. Surviving inner hair cells (IHCs) or outer hair cells (OHCs) were counted over a $100 \mu \mathrm{m}$ longitudinal distance from four randomly selected fields in the basal turn of each culture. The average of the cell counts from these was taken as one sample. All statistical analysis was performed using the one-way analysis of variance (ANOVA) with post-hoc multiple comparisons using the Bonferroni adjusted $p$ values with a value of $p<0.01$ considered significant.

\section{TdT-mediated dUTP-biotin nick end labeling (TUNEL)} method

After the explants were fixed with $4 \%$ paraformaldehyde in the same manner as in phalloidin-FITC staining, TUNEL labeling was performed using an ApopTag Peroxidase In Situ Apoptosis Detection Kit (CHEMICON International, Temecula, CA, USA). The tissue was incubated in terminal deoxynucleotidyl transferase (TdT) enzyme solution in a humidifier for 2 hours at $37^{\circ} \mathrm{C}$. A stop/wash buffer was added to the dish, and the tissue was incubated for $10 \mathrm{~min}$. The specimens were exposed to digoxigenin for $30 \mathrm{~min}$ and then were reacted with diaminobenzidine for $3 \mathrm{~min}$. Additionally, hematoxylin for nuclear staining was used. These cochlear explants were observed and photographed with a microscope (ZEISS).

\section{Results}

Phalloidin FITC staining: Neomycin damage in cochlear cultures

Phallodin was used as a marker to identify surviving hair cells in cochlear explant cultures, as it binds to F-actin, which is highly enriched in the stereociliary bundles of the hair cell. FITCconjugated phalloidin intensely labeled the IHC and $\mathrm{OHC}$ stereochilia bundles allowing easy identification of hair cells present. Hair cells were counted as surviving if stereochilia bundle labeling was clear enough to identify each cell.

The orderly arrangement of the three rows of OHCs and a single row of IHCs in a control tissue is shown in Fig. 1A. After 2 days in a normal medium, neomycin was added at $0.2 \mathrm{mM}$, and incubated for $48 \mathrm{hrs}$. There was massive loss of OHCs, but IHCs were not missing (Fig. 1B). On the other hand, almost all hair cells were not present after treatment with $1 \mathrm{mM}$ neomycin (Fig. 1C). The numbers of surviving hair cells in the control and the neomycin-treated groups are shown in Fig. 2A (OHCs) and Fig. 2B (IHCs). Compared with the control, the significant loss of surviving hair cells was observed at $0.1 \mathrm{mM}$ or higher concentrations of neomycin in OHCs $(p<$ $0.01)$ and at $0.4 \mathrm{mM}$ or higher concentrations of neomycin in IHCs $(p<0.01)$. These data showed that cochlear hair cells were damaged by neomycin in a dose-dependent manner, and that IHCs were more resistant than $\mathrm{OHCs}$ to aminoglycoside ototoxicity.

\section{Phalloidin FITC staining: Protective effects of leupeptin and $B A F$}

To determine the dose of leupeptin, we performed a dose-dependent study by examining different concentrations ranging from 2 to 40 $\mu \mathrm{g} / \mathrm{ml}$ in the cultures (Fig. 3). Administration of leupeptin was significantly effective at $4 \mu \mathrm{g} / \mathrm{ml}$ or higher concentrations on OHC survival $(p<0.01)$ (Fig. 3A). After neomycin $(1 \mathrm{mM})$ treatment, the protective effect of leupeptin on OHCs was saturated at a concentration of $6-40 \mu \mathrm{g} / \mathrm{ml}$, whereas there was significant effect on IHC survival only at $10 \mu \mathrm{g} / \mathrm{ml}$ leupeptin (Fig. 3B). Consequently, we determined that the effective dose of leupeptin was $10 \mu \mathrm{g} / \mathrm{ml}$. In addition, to determine the effective dose of BAF, we cultured cochlear explants with $200 \mu \mathrm{M}$ or $500 \mu \mathrm{M}$ of BAF as in previous studies (Wang et al. 1999; Cheng et al. 1999), without neomycin for 4 days. However, almost all hair cells were lost at $500 \mu \mathrm{M}$ of BAF (data not shown). On the other hand hair cell loss was not observed in $200 \mu \mathrm{M}$ of BAF. Therefore we 

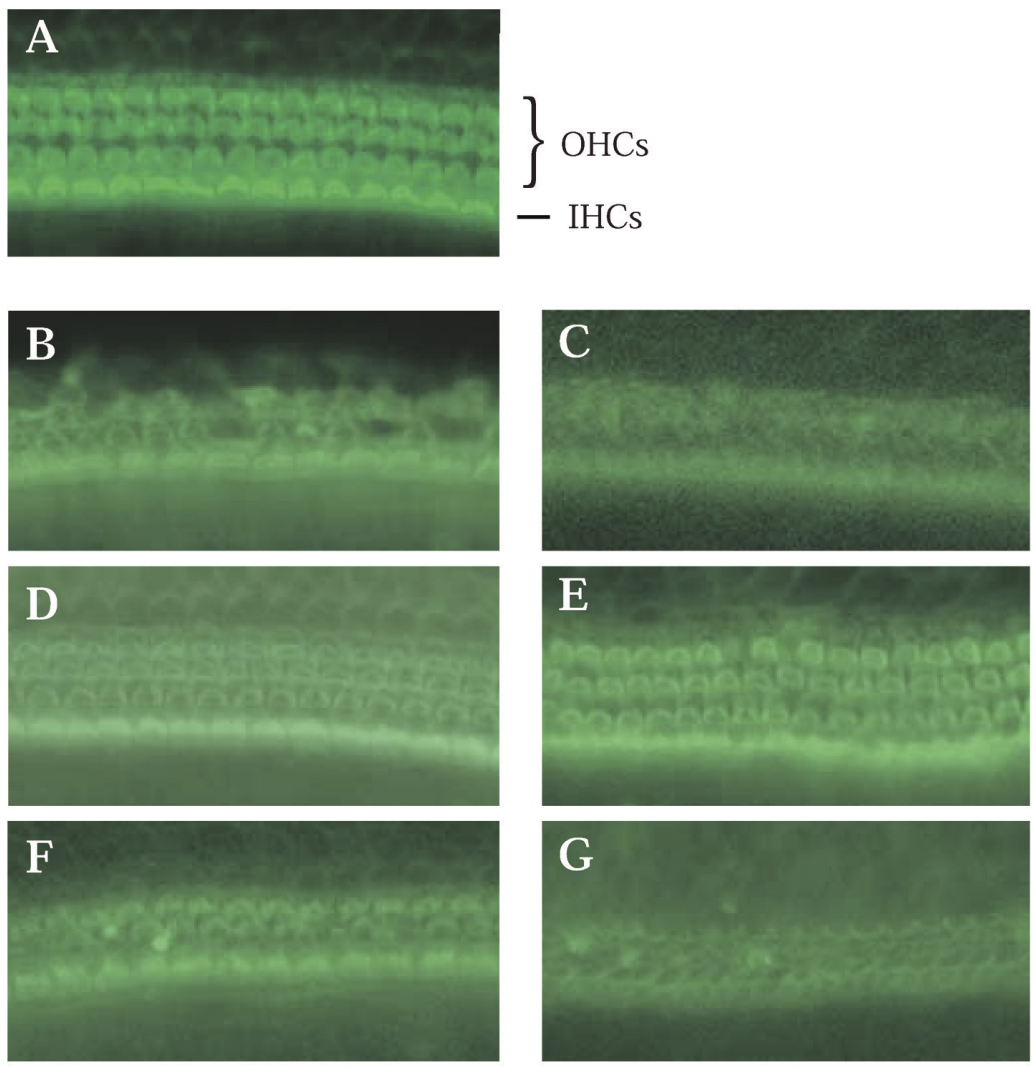

$25 \mu \mathrm{m}$

Fig. 1. Photographs of cochlear hair cells in each culture condition.

Photographs of cochlear hair cells labeled by phalloidin-FITC that were cultured for 4 days in various medium conditions. A: control, cultured in normal medium. The three rows of OHCs and the single row of IHCs can be clearly seen. B: cultured with $0.2 \mathrm{mM}$ neomycin. There was massive loss of OHCs, but IHCs were not damaged. C: cultured with $1 \mathrm{mM}$ neomycin. Almost all hair cells were missing. D: pretreated with leupeptin $10 \mu \mathrm{g} / \mathrm{ml}$ and added neomycin $0.2 \mathrm{mM}$ was similar to the control tissue. E: pretreated with leupeptin $10 \mu \mathrm{g} / \mathrm{ml}$ and added neomycin $1 \mathrm{mM}$. Surviving OHCs were increased to nearly equal to the control. However, the effect of leupeptin on IHCs was less than that of OHCs. F: pretreated with BAF $200 \mu \mathrm{M}$ and added neomycin $0.2 \mathrm{mM}$. Nearly half of OHCs were damaged. G: pretreated with BAF $200 \mu \mathrm{M}$ and added neomycin $1 \mathrm{mM}$. Almost all hair cells were missing. All photographs are equal magnification.

OHC, outer hair cell; IHC, inner hair cell.

selected $200 \mu \mathrm{M}$ as the optimal dose of BAF.

We analyzed protective effects of leupeptin at $10 \mu \mathrm{g} / \mathrm{ml}$ against neomycin at concentrations of 0.2 and $1 \mathrm{mM}$ (Fig. $1 \mathrm{D}$ and E). The number of surviving hair cells in those leupeptin-treated groups were counted and compared to those in the same concentration of neomycin treated groups (Fig. 4). Increasing the dose of neomycin resulted in further loss of cochlear hair cells, but the addition of leupeptin resulted in a significant increase of surviving OHCs nearly equal to the control (Fig. 4A). The effect of leupeptin on IHCs was statistically significant, but less than that of OHCs $(p<$ 0.01) (Fig. 4B). Fig. $1 \mathrm{~F}$ and $\mathrm{G}$ show the effect of $200 \mu \mathrm{M}$ BAF against $0.2 \mathrm{mM}$ and $1 \mathrm{mM}$ neomycin exposure. After treatment with BAF, the surviving number of OHCs was significantly increased when the neomycin concentration was $0.2 \mathrm{mM}$ ( $p<0.01)$ (Fig. 4A). However, with an increased dose of neomycin to $1 \mathrm{mM}$, few OHCs 

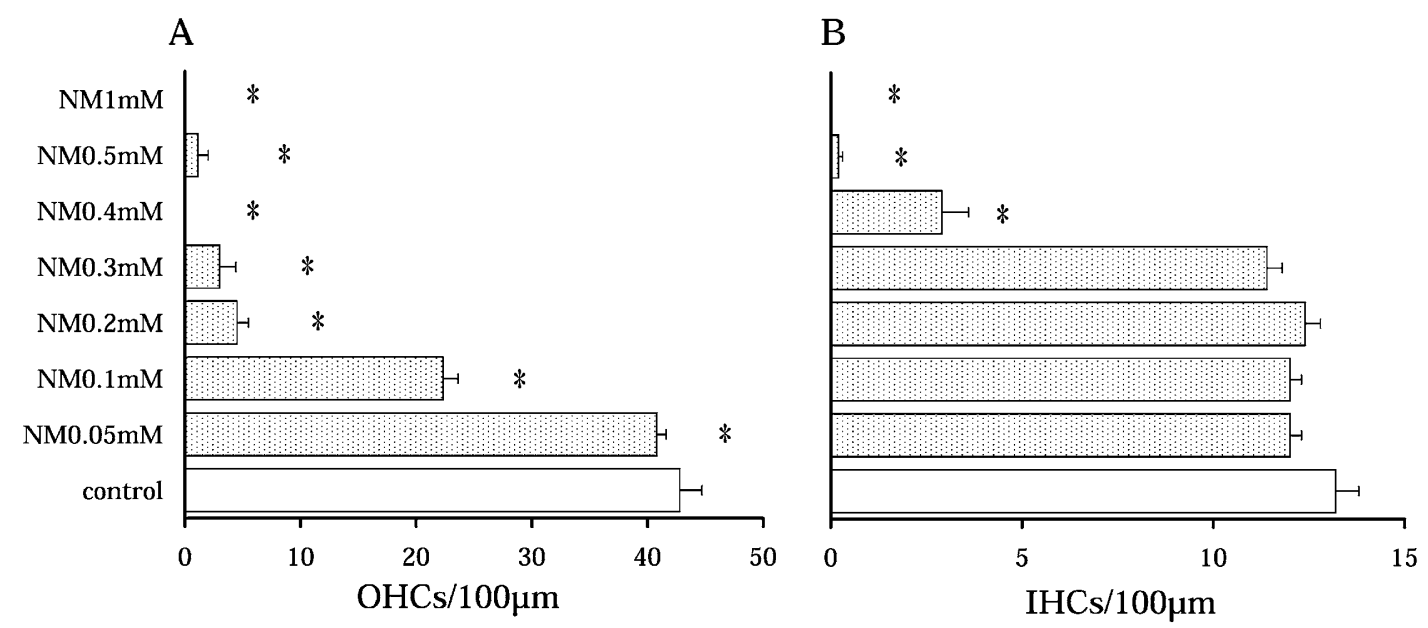

Fig. 2. Relationships between neomycin dose and the average number of surviving hair cells.

The number of surviving OHCs was the X-axis in (A) and that of IHCs was the X-axis in (B). Neomycin dose was at $0.05,0.1,0.2,0.3,0.4,0.5,1.0 \mathrm{mM}$. Statistically significant loss of OHCs started at a lower concentration than IHCs. Each group was $n=10$. NM, neomycin; OHC, outer hair cell; IHC, inner hair cell.

"Statistical significance $(p<0.01)$ when compared to control.

A

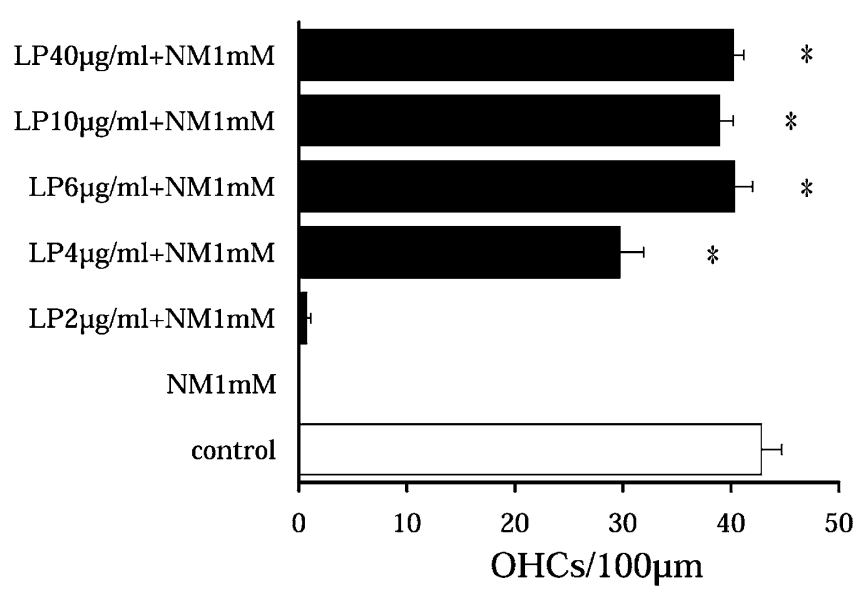

B

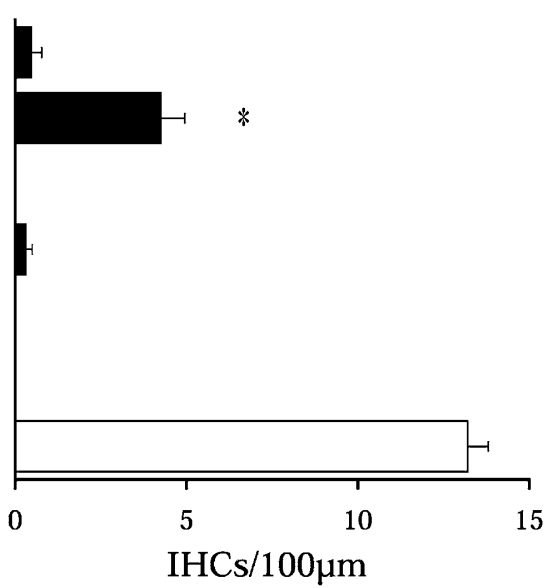

Fig. 3. Dose effect of leupeptin against neomycin $1 \mathrm{mM}$.

Leupeptin was significantly effective at $4 \mu \mathrm{g} / \mathrm{ml}$ or higher concentrations on OHC survival and this result was showed in (A). There was only significant effect on IHC survival at $10 \mu \mathrm{g} / \mathrm{ml}$ of leupeptin and this result was showed in (B).

Control and neomycin $1 \mathrm{mM}$ group was $n=10$. The other groups were $n=8$. NM, neomycin; LP, leupeptin; OHC, outer hair cell; IHC, inner hair cell.

"Statistical significance $(p<0.01)$ when compared to $1 \mathrm{mM}$ of neomycin. 

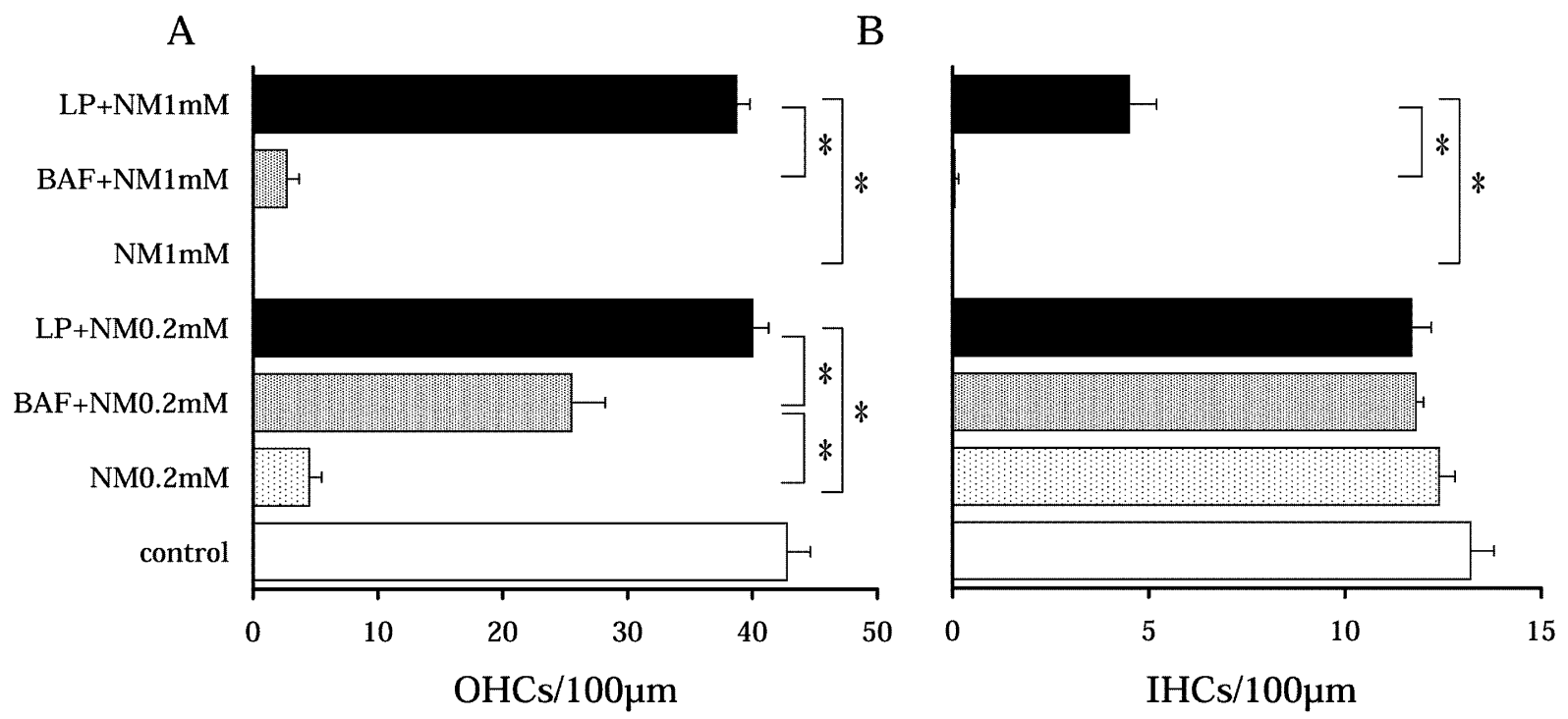

Fig. 4. Effects of leupeptin and BAF on the neomycin toxicity.

The number of surviving OHCs was the X-axis in (A) and that of IHCs was the X-axis in (B). Both $\mathrm{BAF}$ and leupeptin were effective against neomycin ototoxicity, but leupeptin was more effective than BAF.

Each group was $n=10$. NM, neomycin; BAF, Boc-Asp-O-CH3-fluoromethyl ketone $200 \mu \mathrm{M}$; LP, leupeptin $10 \mu \mathrm{g} / \mathrm{ml}$. ${ }^{*} p<0.01$.

were present (Fig. 4A). There was no protective effect of BAF on IHC survival (Fig. 4B). The number of OHCs (neomycin at 0.2 and $1 \mathrm{mM}$ ) and IHCs (at neomycin $1 \mathrm{mM}$ ) in the BAF treated group were significantly less than those of the leupeptin treated group $(p<0.01)$.

\section{TUNEL labeling}

There was a regular array composed of one row of IHCs and three rows of OHCs, and there were no TUNEL labeled cells in control tissue (Fig. 5A). Many TUNEL positive cells were observed in the cochlea cultured with $1 \mathrm{mM}$ of neomycin and all labeled cells were in the area of hair cells present (Fig. 5B). In the organ of Corti treated with $10 \mu \mathrm{g} / \mathrm{ml}$ of leupeptin and $1 \mathrm{mM}$ of neomycin, TUNEL positive cells were not identified (Fig. 5C). However, in the tissue cultured with $200 \mu \mathrm{M}$ of BAF and $1 \mathrm{mM}$ neomycin, many positive cells were observed (Fig. 5D) as in the neomycin treated group. From these results, leupeptin could protect cochlear hair cells from apoptosis induced by neomycin.

\section{Discussion}

In the previous studies, the ototoxicity of aminoglycoside has been investigated. At present, it is suggested that the inner ear hair cell death induced by aminoglycide is apoptosis. In 1985, Forge (1985) indicated that degenerative changes of OHCs in the cochlea following chronic aminoglycoside teratment showed some morphological features similar to apoptosis. This degeneration of hair cells has been reported to involve apoptosis ( $\mathrm{Li}$ et al. 1995; Nakagawa et al. 1997; Lenoir et al. 1999; Forge and Li 2000). Apoptosis is associated with the fragmentation of chromatin into a characteristic 180 to 200-bp DNA ladder. This DNA ladder can be detected by a reaction with $\mathrm{TdT}$, which incorporates nucleotides into the free $3^{\prime}-\mathrm{OH}$ ends of the DNA molecule. Hence, cells undergoing apoptosis have large numbers of these DNA fragments, which can be detected in situ by the TUNEL method (Gavrieli et al. 1992). DNA fragmentation of hair cells induced by aminoglycoside treatment was 

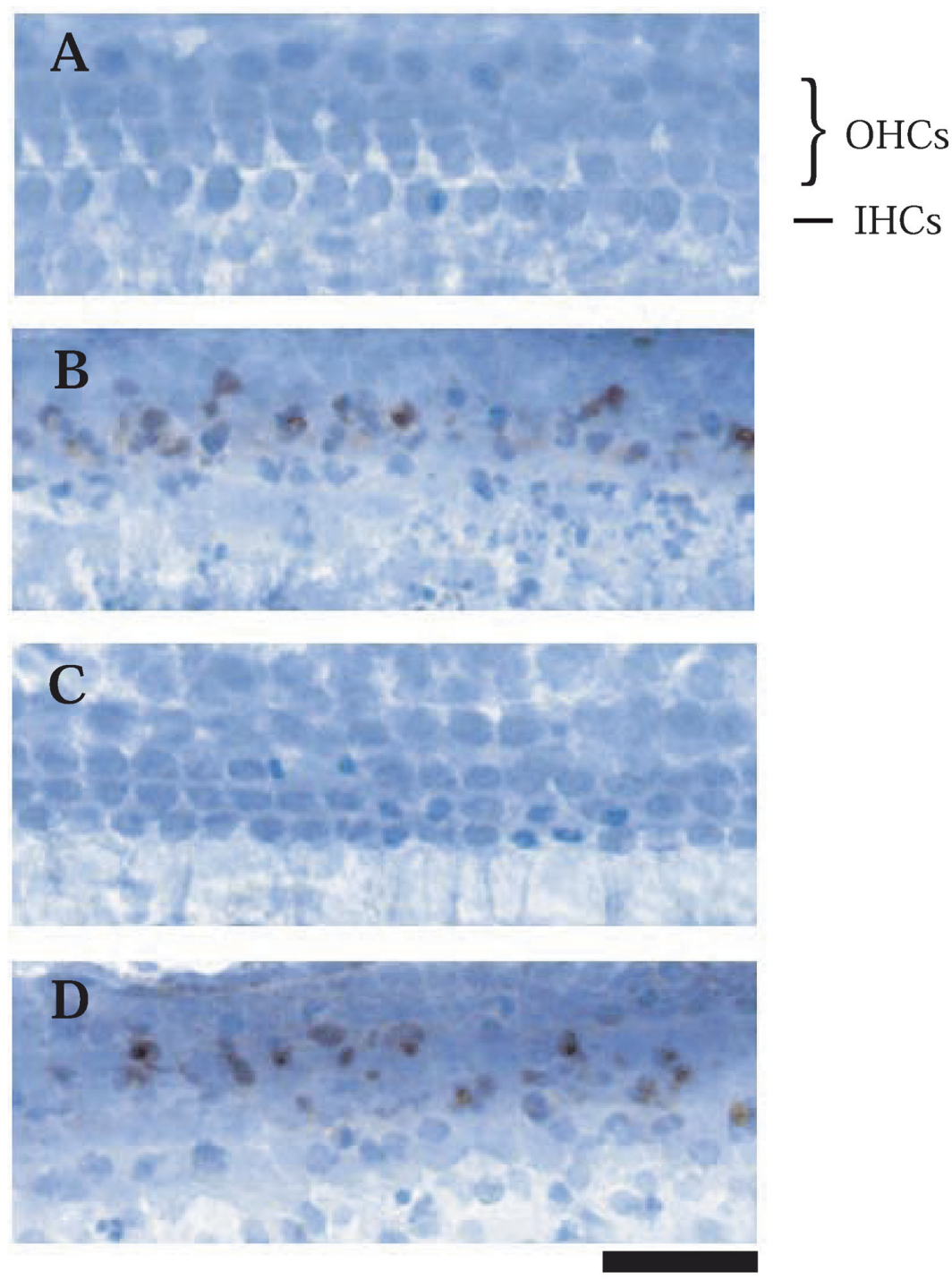

$25 \mu \mathrm{m}$

Fig. 5. Photographs of TUNEL labeling.

A: control, B: neomycin $1 \mathrm{mM}$, C: leupeptin $10 \mu \mathrm{g} / \mathrm{ml}+$ neomycin $1 \mathrm{mM}$, D: BAF $200 \mu \mathrm{M}+$ neomycin $1 \mathrm{mM}$. Many TUNEL positive cells stained brown were observed in (B) and (D) but not in (A) and $(\mathrm{C})$.

identified in the mouse (Nakagawa et al. 1998) and chick (Matsui et al. 2002) using this method. In the present study, after treatment with neomycin, many TUNEL labeled cells which had DNA fragments were observed in the region of hair cells present. These results indicate that ototoxicity due to neomycin induced apoptosis of cochlear hair cells.

Programmed cell death in apoptosis occurs via an orderly series of cellular events (Raff
1998). It is considered that caspase is the key enzyme of the cascade of apoptosis in many organs. Caspase inhibitors prevent apoptosis in many types of neurons (Salvesen and Dixit 1997) and in auditory and vestibular hair cells (Liu et al. 1998; Forge and Li 2000; Matsui et al. 2002). In the present study, the general caspase inhibitor $\mathrm{BAF}$ promoted OHC survival when used in conjunction with $0.2 \mathrm{mM}$ of neomycin. This is comparable with the protective effect of $\mathrm{BAF}$ in 
cultured chick utricles (Matsui et al. 2002). However, approximately half of OHCs treated wtih $0.2 \mathrm{mM}$ of neomycin were not rescued by BAF. When used in conjunction with $1 \mathrm{mM}$ of neomycin, BAF did not protect OHCs and IHCs. These observations suggest that a caspaseindependent pathway could mediate some hair cell death following neomycin.

Calpain, which is a calcium-dependent cysteine protease, is activated when intracellular calcium levels increase (Sorimachi 2000; Hata et al. 2001). Intracellular $\mathrm{Ca}^{2+}$ ions of hair cells are closely linked to a variety of neuronal processes such as changes in membrane conductance, synaptic, activation, and transmitter secretion (Ikeda 2004). Previous studies have shown that aminoglycoside antibiotics cause a dose-dependent increase in intracellular calcium levels in avian hair cells in organotypic cultures (Hirose et al. 1999). The increase in intracellular calcium suggests that neomycin treatment might lead to upregulation of calcium-activated proteases resulting in the breakdown of cytoskeletal and membrane proteins, phosphatases, kinases, and transcription factors, conclusively leading to hair cell death (Bartus et al. 1995). More recently, the increase in calpain immunolabeling in hair cells after aminoglycoside treatment was indicated (Ding et al. 2002), and it was also suggested that leupeptin protected cochlear and vestibular hair cells from gentamicin treatment (Ding et al. 2002).

Leupeptin is one of the common inhibitors of calpains and has been shown to inhibit programmed cell death in other cells (Montenez et al. 1994). Regarding the inner ear, leupeptin was proven to protect auditory hair cells from acoustic overstimulation (Salvi et al. 1998; Wang et al. 1999), hypoxia and neurotrophin-withdrawal (Cheng et al. 1999).

In the present study, leupeptin increased the surviving number of hair cells following neomycin treatment, and reduced TUNEL positive cells. These findings suggest that calpain participates in the auditory hair cell death induced by neomycin treatment. Furthermore, the administration of leupeptin was more effective than that of BAF. We therefore suggest that calpain rather than caspase is involved in the apoptosis pathway of auditory hair cells. Additionally, the effect of leupeptin is more significant on OHCs than IHCs. It has been well known that OHCs were susceptible to damage by several ototoxins including aminoglycoside. The susceptibility to damage caused by aminoglycoside of $\mathrm{OHCs}$ has been investigated repeatedly and the differences between $\mathrm{OHCs}$ and IHCs have been well known. For example, KCNQ4 encodes a $\mathrm{K}^{+}$channel that is exclusively localized in the outer hair cells and KCNQ4 mutation leads to progressive hearing loss (Ikeda 2004). In the present study, the protective effect of leupeptin was more significant in OHCs than that in IHCs, and statistically significant loss of OHCs was induced by neomycin at a lower concentration than that of IHCs.

It has been reported that the administration of leupeptin to primates facilitated the morphological and functional recovery of damaged peripheral nerves without causing any hematological problems (Badalamente et al. 1989). When leupeptin is delivered into scala tympani, it protects the hair cells from acoustic overstimulation (Salvi et al. 1998; Wang et al. 1999). Taken together, we suggest the possibility for the clinical use of leupeptin.

\section{Acknowledgments}

The authors thank all of the assistants who participated in this research. They also thank Hideichi Kurotaki and Ryuuichi Wada, for their invaluable technical advice.

\section{References}

Badalamente, M.A., Hurst, L.C. \& Stracher, A. (1989) Neuromuscular recovery using calcium protease inhibition after median nerve repair in primates. Proc. Natl. Acad. Sci. USA, 86, 5983-5987.

Bartus, R.T., Elliott, P.J., Hayward, N.J., Dean, R.L., Harbeson, S., Straub, J.A., Li, Z. \& Power, J.C. (1995) Calpain as a novel target for treating acute neurodegenerative disorders. Neurol. Res., 17, 249-258.

Cheng, A.G., Huang, T., Stracher, A., Kim, A., Liu, W., Malgrange, B., Lefebvre, P.P., Schulman, A. \& Van de Water, T.R. (1999) Calpain inhibitors protect auditory sensory cells from hypoxia and neurotrophin-withdrawal induced apoptosis. Brain Res., 850, 234-243.

Ding, D., Stracher, A. \& Salvi, R.J. (2002) Leupeptin protects cochlear and vestibular hair cells from gentamicin ototoxic- 
ity. Hear. Res., 164, 115-126.

Forge, A. (1985) Outer hair cell loss and supporting cell expansion following chronic gentamicin treatment. Hear. Res., 19, 171-182.

Forge, A. \& Li, L. (2000) Apoptotic death of hair cells in mammalian vestibular sensory epithelia. Hear. Res., 139, 97-115.

Gavrieli, Y., Sherman, Y. \& Ben-Sasson, S.A. (1992) Identification of programmed cell death in situ via specific labeling of nuclear DNA fragmentation. J. Cell Biol., 119, 493-501.

Hata, S., Sorimachi, H. \& Suzuki, K. (2001) Structure and function of calpain superfamily. Seikagaku, 73, 1129-1140. (in Japanese)

Hirose, K., Westrum, L.E., Stone, J.S., Zirpel, L. \& Rubel, E.W. (1999) Dynamic studies of ototoxicity in mature avian auditory epithelium. Ann. NY Acad. Sci., 884, 389-409.

Ikeda, K. (2004) Gene-based deafness research: ion transport and hearing. Tohoku J. Exp. Med., 202, 1-11.

Johnson, D.E. (2000) Noncaspase proteases in apoptosis. Leukemia, 14, 1695-1703.

Kopke, R., Allen, K.A., Henderson, D., Hoffer, M., Frenz, D. \& Van de Water, T. (1999) A radical demise: toxins and trauma share common pathways in hair cell death. Ann. NY Acad. Sci., 884, 171-191.

Lenoir, M., Daudet, N., Humbert, G., Renard, N., Gallego, M., Pujol, R., Eybalin, M. \& Vago, P. (1999) Morphological and molecular changes in the inner hair cell region of the rat cochlea after amikacin treatment. J. Neurocytol., 28, 925-937.

Li, L., Nevill, G. \& Forge, A. (1995) Two modes of hair cell loss from the vestibular sensory epithelia of the guinea pig inner ear. J. Comp. Neurol., 355, 405-417.

Liu, W., Staecker, H., Stupak, H., Malgrange, B., Lefebvre, P. \& Van de Water, T.R. (1998) Caspase inhibitors prevent cis- platin-induced apoptosis of auditory sensory cells. Neuroreport, 9, 2609-2614.

Matsui, J.I., Ogilvie, J.M. \& Warchol, M.E. (2002) Inhibition of caspases prevents ototoxic and ongoing hair cell death. $J$. Neurosci., 22, 1218-1227.

Montenez, J.P., Delaisse, J.M., Tulkens, P.M. \& Kishore, B.K. (1994) Increased activities of cathepsin B and other lysosomal hydrolases in fibroblasts and bone tissue cultured in the presence of cysteine proteinases inhibitors. Life Sci., 55, 1199-1208.

Nakagawa, T., Yamane, H., Shibata, S. \& Nakai, Y. (1997) Gentamicin ototoxicity induced apoptosis of the vestibular hair cells of guinea pigs. Eur. Arch. Otorhinolaryngol., 254, 9-14.

Nakagawa, T., Yamane, H., Takayama, M., Sunami, K. \& Nakai, Y. (1998) Apoptosis of guinea pig cochlear hair cells following chronic aminoglycoside treatment. Eur. Arch. Otorhinolaryngol., 255, 127-131.

Raff, M. (1998) Cell suicide for beginners. Nature, 396, 119-122.

Romand, R. \& Chardin, S. (1999) Effects of growth factors on the hair cells after ototoxic treatment of the neonatal mammalian cochlea in vitro. Brain Res., 825, 46-58.

Salvesen, G.S. \& Dixit, V.M. (1997) Caspases: intracellular signaling by proteolysis. Cell, 91, 443-446.

Salvi, R.J., Shulman, A., Stracher, A., Ding, D. \& Wang, J. (1998) Protecting the inner ear from acoustic trauma. Int. Tinnitus J., 4, 11-15.

Sorimachi, H. (2000) Structure and function of calpain and its homologues. Seikagaku, 72, 1297-1315. (in Japanese)

Wang, J., Ding, D., Shulman, A., Stracher, A. \& Salvi, R.J. (1999) Leupeptin protects sensory hair cells from acoustic trauma. Neuroreport, 10, 811-816. 